Escritura y Pensamiento

20-24(40-48), 2021, 303-316

\title{
ROLES DEL LOCUTOR EN “EL FUMADOR DE PIPA”
}

\section{ROLES OF THE ANNOUNCER IN "THE PIPE SMOKER"}

\section{PAPÉIS DO LOCUTOR EM "O FUMANTE DE CACHIMBO"}

\author{
Josué Yared Medina Huamán ${ }^{1}$ \\ Universidad Nacional Mayor de San Marcos \\ Esandino - Estudios Andinos de Interculturalidad: quechua y aymara \\ josueyared.medina@unmsm.edu.pe \\ ORCID: 0000-0001-6229-9034
}

Recibido: $11 / 03 / 21$

Aceptado: 20/03/21

1 Licenciado en Educación por la Universidad Nacional de Educación Enrique Guzmán y Valle (2014), donde también cursó la maestría en Docencia Universitaria (2015); desde el 2018 estudia la maestría en Literatura Peruana y Latinoamericana en la Universidad Nacional Mayor de San Marcos. 


\section{Resumen}

Esta investigación estudia los roles del locutor en "El fumador de pipa" para interpretar cómo este sujeto intratextual se relaciona con otros sujetos intra y extratextuales de La torre de las paradojas. Para este fin, se amplía la teorización sobre el sujeto lírico (Slawinski, 1989) mediante los aportes de investigaciones recientes sobre el locutor y sus roles. Como resultado, se evidencia al personaje como reflejo de la psique del locutor. De esta manera, se concluye que el personaje solitario y meditativo fuma tabaco para potenciar sus facultades cognitivas y así conectarse con instancias superiores. De esta manera, se advierte deshumanizado como la bella escultura del animal que piensa.

Palabras clave: vanguardia, indigenismo, locutor, tabaco, Atahualpa Rodríguez.

\section{Abstract}

This research studies the roles of the announcer in "The pipe smoker" to interpret how this intratextual subject is related to other intra- and extratextual subjects of The Tower of Paradoxes. To this end, theorization about the lyrical subject is expanded (Slawinski, 1989) through the contributions of recent research on the speaker and his roles. As a result, the character is evidenced as a reflection of the speaker's psyche. In this way, it is concluded that the solitary and meditative character smokes tobacco to enhance their cognitive faculties and thus connect with higher instances. In this way, he sees himself dehumanized as the beautiful sculpture of the animal that he thinks.

Keywords: avant-garde, indigenism, announcer, tobacco, Atahualpa Rodríguez.

\section{Resumo}

Esta pesquisa estuda os papéis do locutor em "O fumante de cachimbo" para interpretar como esse sujeito intratextual se relaciona com outros sujeitos intra e extratextuais de A Torre dos Paradoxos. Para tanto, amplia-se a teorização sobre o sujeito lírico (Slawinski, 1989) por meio das contribuições de pesquisas recentes sobre o locutor e seus papéis. Como resultado, o personagem é mostrado como um reflexo da psique do locutor. Desta forma, conclui-se que o caráter solitário e meditativo fuma tabaco para aprimorar suas faculdades cognitivas e, assim, conectar-se com instâncias superiores. Desse modo, é visto tão desumanizado quanto a bela escultura do animal pensante. 
Palavras-chave: vanguarda, indigenismo, emissora, fumo, Atahualpa Rodríguez.

\section{Objetivo}

Mediante el prestigio simbolista de los paraísos artificiales, el modernismo retoma el evasionismo parnasiano para hacer exótica la obra de arte como reflejo de una individualidad elevada, una aristocracia del alma superior al mercantilismo cientificista burgués. Así, los personajes decadentes se aíslan en torres para no comulgar con la inmediatez y utilidad burguesa. En soledad, se potencian las facultades creativas del ego que pretende trascender la realidad envilecida de cristianismo languidecido. La poetización sobre los caídos como Satán y Prometeo les otorga una consciencia superior como mediadores entre dioses y hombres. A principios del siglo XX, además de la necesidad de enrarecer la obra artística como manifestación de la aristocracia del alma creadora, Valdelomar, Vallejo y Mariátegui suman la necesidad de comunicarse con las masas. De este modo, la relación entre sujetos convocados por el poema cobra características particulares que repercuten en el contenido y forma de los textos literarios. Esto influye en la polémica del vanguardismo (Lauer, 2001), donde se discuten las innovaciones poéticas de La torre de las paradojas (1926) de César Augusto Rodríguez Olcay (Atahualpa Rodríguez).

En la obra del arequipeño, se ha estudiado su poesía (Cornejo, 2018) de melancólica interiorización postmodernista (Segura, 2012, 2016), La torre de las paradojas (Pantigoso, 1961) y su espiral introyectiva (Pantigoso, 1970), donde se evidencia la constante confrontación del ego creador con otras instancias del ser para producir la obra de arte. Sin embargo, no se ha estudiado el sujeto lírico. En ese sentido, esta investigación estudia los roles del locutor en "El fumador de pipa” para ca- 
racterizar cómo este sujeto intratextual se relaciona con otros sujetos intra y extratextuales de La torre de las paradojas. Para este fin, se amplía la teorización sobre el sujeto lírico, mediante los aportes de investigaciones recientes sobre este interlocutor.

\section{Método: roles del locutor}

El locutor (García-Bedoya, 2019; Fernández, 2021) es una subcategoría del sujeto lírico (Slawinski, 1989), sujeto poético (Gallegos, 2006). Sin embargo, para una mayor especificidad y por sus características operativas, en esta investigación se estudia "El fumador de pipa" mediante el análisis del locutor y sus roles. Es decir, su relación con los sujetos representados en su enunciación (personaje); el alocutario a quien dirige su enunciación; el sí mismo del locutor; los otros sujetos intratextuales del poemario (poeta-lector); los sujetos del referente de La torre de las paradojas (autor-sociedad). Esto se complementa con los aportes sobre el sujeto lírico en sus reconfiguraciones en la poesía hispanoamericana de vanguardia (Castañeda, 2011), como mestizo en la poesía de las memorias culturales (Mansilla, 2011), como sujeto decadente (De Rosa, 2000) como sujeto juvenil drogado a principios del siglo XX en el Perú (Sánchez, 2007). Asimismo, debido a que autores como Julián del Casal o Julio Herrera y Reissig dieron énfasis publicitario a su relación con los paraísos artificiales; el análisis de los roles del locutor supera el biografismo anecdotario como vicio interpretativo frecuente en el estudio de fumadores textuales.

\section{Interpretación: discusión de resultados}

Tabla 1

Análisis ritmico 


\begin{tabular}{|c|c|c|c|}
\hline Poema "E1 fumador de pipa" & $\begin{array}{l}\text { Silabas } \\
\text { poéticas }\end{array}$ & $\begin{array}{l}\text { Cimas pro- } \\
\text { sódicas }\end{array}$ & $\begin{array}{l}\text { Final de } \\
\text { verso }\end{array}$ \\
\hline $\begin{array}{c}\text { Con/ los/o/jos/ per/di/dos/ en/ la/ } \\
\text { cal/ma/ del/ vien/to/ }\end{array}$ & 14 & $3,6,10,13$ & A, ento \\
\hline \multirow{3}{*}{$\begin{array}{l}\text { re/co/gen/ sus/ pu/pi/las/ el/ pai/sa/ } \\
\text { je, y/ se a/fa/na/ } \\
\text { por/ bus/car/ en/ su/ne/gra/ ca/be/ } \\
\text { za u/na/ ven/ta/na/ }\end{array}$} & 14 & $2,6,10,13$ & $\mathrm{~B}$, ana \\
\hline & 14 & $3,6,9,10,13$ & $\mathrm{~B}$, ana \\
\hline & 14 & $1,4,6,10,13$ & A, ento \\
\hline \multicolumn{4}{|l|}{$\begin{array}{l}\mathbf{p a} / \mathrm{ra} / \mathrm{que} / \mathbf{p a} / \mathrm{se} \mathrm{el} / \mathbf{a} / \mathrm{la} / \mathrm{de} \mathrm{un} / \mathrm{te} / \\
\text { naz/ pen/sa/mien/to./ }\end{array}$} \\
\hline \multirow{4}{*}{$\begin{array}{c}\text { la/ vi/da en/ la/ bru/mo/sa/ ma/de/ } \\
\text { ja/ de/ su a/lien/to./ }\end{array}$} & 14 & $1,4,6,9,13$ & $\mathrm{~B}$, ento \\
\hline & 14 & $4,6,11,13$ & A, ana \\
\hline & 14 & $2,4,6,9,13$ & A, ana \\
\hline & 14 & $2,6,9,13$ & $\mathrm{~B}$, ento \\
\hline $\begin{array}{c}\mathrm{Su} / \mathrm{mer} / \mathbf{g i} / \mathrm{do} \text { en/ si/ } \mathbf{m i s} / \mathrm{mo} / \mathbf{c o} / \mathrm{mo} \\
\mathrm{en} / \mathrm{la} / \mathbf{s e d} / \mathrm{de} \text { un/ ri/to,/ }\end{array}$ & 14 & $3,5,6,8,11,13$ & $\mathrm{C}$, ito \\
\hline \multirow{2}{*}{$\begin{array}{c}\text { sus/ o/jos/ van/ tor/nán/do/se/ dos/ } \\
\text { go/tas/ de in/fi/ni/to/ }\end{array}$} & 15 & $2,4,6,9,10,14$ & $\mathrm{C}$, ito \\
\hline & 14 & $2,6,8,11,13$ & $\mathrm{D}$, ensa \\
\hline \multicolumn{4}{|l|}{$\begin{array}{c}\text { que/ pen/den/ de/ la/ na/da/ so/bre/ } \\
\text { la/ na/da in/men/sa?/ }\end{array}$} \\
\hline \multicolumn{4}{|l|}{$\begin{array}{l}\text { Y en/ el/ fon/do es/te/la/rio/ de un/ } \\
\text { cie/lo/ de a/gua/fuer/te,/ }\end{array}$} \\
\hline $\begin{array}{c}\text { el/ fu/ma/dor/ de/ pi/pa,/ des/per/ } \\
\text { tán/do/se,/ ad/vier/te/ }\end{array}$ & 15 & $\begin{array}{l}3,6,9,13 \\
4,6,10,14\end{array}$ & $\begin{array}{l}\mathrm{E}, \text { erte } \\
\mathrm{E}, \text { erte }\end{array}$ \\
\hline $\begin{array}{l}\text { que es/ la/ be/lla es/cul/tu/ra/ del/ a/ } \\
\text { ni/mal/ que/ pien/sa./ }\end{array}$ & 14 & $3,6,11,13$ & $\mathrm{D}$, ensa \\
\hline
\end{tabular}

Nota: Análisis del ritmo y la rima de "El fumador de pipa".

En este soneto no se representan el locutor ni el alocutario, sin embargo, mediante la enunciación del locutor se estudia su relación con los otros sujetos del poema. La representación que el enunciatario hace del fumador de pipa se centra en los ojos perdidos durante la contemplación del paisaje fuera de la habitación solitaria en la que se encuentra. Este personaje finisecular medita soñoliento sobre la vida mientras exhala el humo del tabaco. La profundidad de su ensimismamiento desemboca en el arrobamiento en la nada infinita. Al despertar del ensueño meditativo, el fumador obtiene una advertencia sobre sí mismo: es la bella escultura del animal que piensa. Así, puede sinte- 
tizarse la relación entre sujetos del poema mediante la Figura 1. De esta manera, para analizar los roles del locutor en este soneto, se parte de su relación con el sujeto enunciado (personaje) hasta los sujetos líricos.

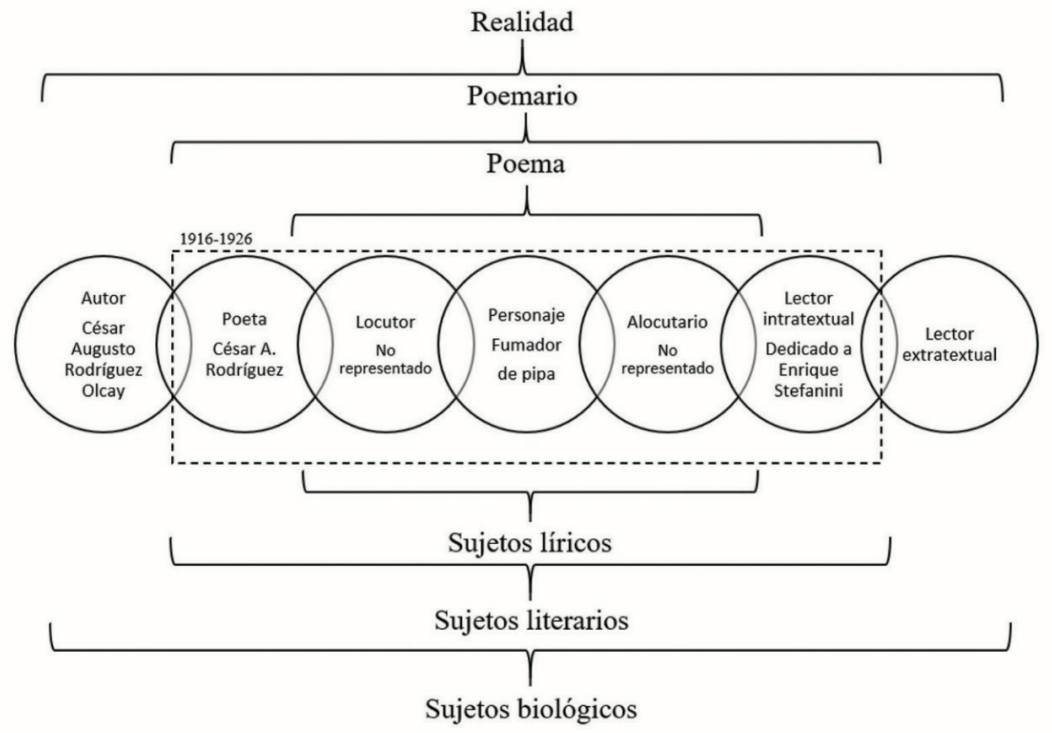

Figura 1: Relación entre sujetos biológicos, literarios y líricos.

En La torre de las paradojas, el locutor es una de las diversas manifestaciones de la psique del poeta. Como una caja china, el poeta manifiesta una parte de sí a través de la enunciación del locutor, que a su vez crea mediante la enunciación un personaje como reflejo de su propia psique. Este personaje se embebe en la nada para verse a sí mismo. Tras la contemplación ensoñadora, despierta de la narcosis con una advertencia narcisista; aplicable también al locutor y poeta quienes lo comunican al alocutario y lector desde sus instancias respectivas. Aunque el poema está dedicado a Enrique Stefanini —director de Nuestra América, donde se editó La torre de las paradojas-, la instancia de lector no es exclusiva y excluyentemente suya. 
Sin embargo, se requiere una investigación más específica para estudiar su función apelativa subyacente.

El locutor en La torre de las paradojas se transfigura en diversos personajes para hablar a través de ellos, sobre un aspecto psíquico de sí mismo. Esto se debe a la estrecha relación que se establece entre los sujetos líricos a principios del siglo $\mathrm{XX}$, donde la obra de arte exquisita como reflejo del artista raro y misántropo coincide con la concepción de la obra de arte que extralimita la razón como producto de un ego casi divino. Así, la representación completa del locutor se efectúa mediante el total de poemas y los aspectos psíquicos que revele sobre sí a través de los personajes de su enunciación. Como en "Psicología felina" o "Ante el cadáver de un asno"; se interpreta la psique del personaje fumador pensador solitario como un reflejo de la psique del locutor. A través del locutor, se estabiliza la voz del poeta y el lector amplía el sentido de los versos mediante la confrontación entre poemas. Del mismo modo, el léxico de los títulos son palabras recurrentes en los poemas. Esto sugiere que, para ampliar el significado de una palabra de La torre de las paradojas, debe buscarse en el índice como título de otro poema que permita comprender mejor su significación poética. Así, se debe interpretar el poemario como un universo accesible mediante la comunicación entre poemas, como fragmentos del mundo posible.

Los locutores y personajes fumadores de La torre de las paradojas recurren a la embriaguez del tabaco para paliar la angustia de vivir. En "Humo", el locutor fuma el perfume de otros dias con nostalgia; frente a "El fumador de pipa", donde el ensimismamiento en la propia vida prioriza lo cognitivo, bello y creativo. En "Misticismo" el locutor fumador melancólico contempla la pradera a través de la ventana mientras su pensamiento se disipa lento como el humo; por su parte, en "El fumador de pipa", el personaje sombriamente iluso devana la vida en la brumosa madeja de su aliento mientras se embebe en el paisaje para encontrar una ventana en su negra cabeza. En "Del 
suburbio", para aburrirse menos, el caballero fuma habanos mientras espera a Lilí, la pecadora tierna. A su vez, en "Gris", la embriaguez del cigarro palia el cansancio poscoital del locutor. Complementariamente, en "Oro", la pipa en los dientes hace que fluya el espíritu, para acompañar la embriaguez erótica desencadenada por una mujer alemana de ensueño. Sin embargo, en "El fumador de pipa" el personaje solitario muerde la amarga pipa sin ser interrumpido en su proceso meditativo, por lo que en su consumo predomina el goce mental sobre el sensual. Del mismo modo, en "Novilunio", fumar inicia los trances de intensa meditación y estelar arrobamiento en los que se pierde el locutor; donde la soledad potencia la soberanía sobre ego, libre de ataduras sociales a fin de trascender la razón. En esta visión, el locutor se representa a sí mismo como un monolito que quiere escrutar el infinito; sin embargo, el personaje solitario de "El fumador de pipa" ve el infinito y se advierte como la bella escultura del animal que piensa. Por su parte, en "El hombre que no habia hecho nada", el personaje fumador eterno de la exigua colilla de espiras blancas admira su rica biblioteca mientras lanza sombria bocanada con la mirada seca. Así, habita una ruinosa buhardilla debido al maniático ensueño de embeberse en la nada. Sin embargo, en "El fumador de pipa", el personaje soñoliento se embebe en la nada sumergido en sí mismo como en la sed de un rito mientras sus ojos se tornan dos gotas de infinito. Como se evidencia, los fumadores de La torre de las paradojas se relacionan de diversas maneras con su consumo. Asi, el locutor objeto de estudio describe principalmente los ojos del personaje, quien por medio de un estrabismo especial propicia su estelar arrobamiento. Pues paradójicamente debe enceguecerse para obtener una visión especial que le permita mirar dentro de sí. Este ensimismamiento en la nada es propiciado por las cualidades enteógenas del tabaco. Así, la elevación a instancias superiores del ser se manifiesta en los ojos tornados en dos gotas de infinito, ya que solo con una visión ampliada el personaje advertirá el ala de un tenaz pensamiento. 
En el poemario, los escenarios en penumbra $u$ oscuridad intensifican el misterio y complicidad pecaminosa. En estos escenarios, los personajes escapan del tedio en soledad o acompañados por medio del desajuste de los sentidos. Sin embargo, el efecto cognitivo del desajuste de los sentidos propiciado por el humo enteogénico es sacrílego para la iglesia, pues solo el diablo concede la facultad de sacar humo por la boca. Así, frente al cristianismo languidecido que acusa de idolatría a quien fume como los paganos, el locutor construye un fumador de tabaco como conocedor del Satán de Baudelaire y la Esfinge de Herrera y Reissig. Frente a la asociación del ensueño poético con la embriaguez, para el fumador de pipa, el consumo de tabaco potencia sus cualidades cognitivas, porque para él fumar es pensar; donde se goza de un paraíso artificial ensimismado para encontrar el ala de un tenaz pensamiento vinculado a "la vida" que devana en la brumosa madeja de su aliento. Como luciferino Prometeo solitario opuesto a Cronos y Zeus, el personaje fumador consume como en la sed de un rito el producto de su esfuerzo; lo sacrifica a la nada a cambio de un pensamiento. El fumador de pipa consume tabaco y también se consume así mismo en cada combustión. Y se entrega a la nada en cuerpo y mente. Durante el ensimismamiento crea de la nada mediante la amplificación, superposición y confrontación de su yo con otras instancias de su ser. Tras su ensoñación, el fumador de pipa se advierte a sí mismo, pero también es advertido por los otros sujetos convocados por el poema.

Para comprender la paradójica advertencia narcisista del personaje enunciado por el locutor, debe confrontarse a los fumadores del contexto de La torre de las paradojas. A principios del siglo XX, las élites se sirven del discurso médico higienista para representar al indio, negro o chino como irracional e incivilizado. La publicación de la Harrison Narcotic Act (1914) y el ataque de la prensa a los mercados y consumidores que no encajaban en los ideales elitistas de progreso, ocasiona una serie de cambios que afectan la representación dandinesca del fu- 
mador de pipa. Así, la bella representación de un personaje que encarna el placer de fumar meditativamente pasa a significar la encarnación del vicio y el ocio para el utilitarismo industrial. En el continente, se evidencian campañas higienistas, moralizadoras y psiquiátricas contra ciertos consumos y mercados para criminalizarlos. En el Perú, los mercados del tabaco y el opio fueron sistemáticamente marginados. A pesar de que, tras el proyecto ilustrado para la industria tabacalera en la Audiencia de Charcas, 1778-1810, el mercado del tabaco y la hoja de coca significaron la mayor renta del Rey de España en sus posesiones de América. El consumo de estas plantas sagradas también fue importante durante la Guerra de Independencia donde se incorporó al runa andino, campesino como montonero a las filas patriotas con la promesa de sembrar, cosechar y vender cualquier producto de su tierra (incluyendo el tabaco y la coca); por lo que se extinguió el estanco, aunque se mantuvo la alcabala. Del mismo modo, las propiedades de estas plantas cobraron relieve durante la Primera Guerra Mundial y los levantamientos indígenas del sur andino en el contexto de 1920-1923, por el incumplimiento de las promesas modernizadoras de Leguía.

Así, antes de la publicación del poemario, el fumadero de opio y las casas de juego fueron previamente desacreditadas mediante la prensa (Saravia, 2020) pero el Estado no propuso su erradicación, sino solo su regulación para imponer mayores impuestos (Muñoz, 2001). Debido a los migrantes asiáticos y de provincia, la Calle Capón y adyacentes como la de Hoyos, Anticona, Rectora y la calle Yaparió fueron considerados por la prensa limeña (sobre todo entre 1912 y 1916) como abyectos, incivilizados, propicios al crimen y todo tipo de inmoralidades. Sin embargo, en el número 2 de Colónida, se ejerce la defensa del opio como patrimonio de la raza más pensadora y eugénica de la tierra, en oposición al alcohol que aplebeya. A su vez, Valdelomar califica los efectos de la flor de adormidera como una parranda de la inteligencia. Así, en la casa de Percy Gibson, son infaltables las pipas durante las sesiones de El Aquelarre 
como continuación de Colónida. No obstante, frente al exótico opiómano de ensoñaciones orientalistas, el fumador de tabaco de La torre de las paradojas es representado en la cotidianidad aldeana arequipeña como un pensador ensimismado y solitario. Fuma intensamente para obtener una advertencia como producto del extravío en la nada. Esta advertencia lo revela animalizado. El locutor describe un personaje eternamente consciente de sí mismo como un nuevo caído, pues ha sido deshumanizado. Como en "Futura", el fumador de pipa se desengaña del hombre moderno, apóstol de las Bolsas en Gante y Nueva York, pues ha normalizado el abuso y la explotación propia de los nuevos capitales corruptos en el todo el país (Quiroz, 2013). Así, el fumador de pipa supera el arielismo divinizador de tiranos a cambio de un paraíso artificial como mito de progreso. Frente al hombre racionalmente abusivo y opresor en nombre de la modernidad, como programa de saqueo del partido político de turno; el locutor enuncia la representación de la bella escultura del animal que piensa.

Así, en La torre de las paradojas, frente a la modernidad y el mito del progreso que racionaliza el despojo sistemático de los indefensos; el locutor representa mediante su enunciación a un personaje fumador desengañado de la posesión, el tiempo y el espacio como patrones pasajeros para medir el valor de la vida. Al fumar tabaco, el personaje quema su tiempo, es decir, su vida para comprender qué es la vida. Nuevamente la paradoja de Sócrates frente a la inscripción del oráculo. Edipo frente a la enigmática Esfinge de paradojas. El locutor representa un fumador de pipa animalizado, bello como todo caído, cuyo don y pecado radica en pensar, es decir, fumar tabaco en soledad para sumergirse en sí mismo. Aunque la paradoja y la influencia de Baudelaire en el poemario requieren amplios estudios específicos, el fumador de pipa es un pensador que paradójicamente se piensa a sí mismo; pues responde al enigma de la existencia a partir de su propio ser, donde se advierte como la bella escultura del animal que piensa. Esto se relaciona con Baudelaire, 
quien describe los efectos del haschisch mediante una paradoja donde el fumador cree estar sentado sobre su pipa, mientras es fumado por la pipa y se desvanece en el humo azulado. Así, en "El fumador de pipa", los ojos del personaje se pierden en el paisaje externo para contemplar el interno; mientras la hilazón celeste que mana del tabaco posibilita contemplar momentáneamente el infinito a partir del sumergimiento en su propio yo.

\section{Conclusión}

Como se ha demostrado, tras el análisis de los roles del locutor en "El fumador de pipa", el personaje solitario y meditativo fuma tabaco como una herramienta cognitiva, pues se potencian sus facultades y se conecta con instancias superiores a su existencia. En ese sentido, el personaje fumador de pipa se evidencia como una instancia de la psique del locutor. A su vez, esta investigación revela la necesidad de investigaciones específicas para interpretar la función de las paradojas, la influencia de Baudelaire, el desajuste de los sentidos, la videncia o lo maldito en el poema; así como estudios comparativos entre los fumadores del poemario. El método empleado para analizar al locutor en el poema sitúa la interpretación desde el texto y escala progresiva y pertinentemente hacia otros ámbitos de estudio. Esto evita que la información sobre el consumo anecdotario del autor opaque la interpretación de los sujetos textuales, sin descuidar el vínculo entre el contexto y el poemario. Del mismo modo, al estudiar al fumador de pipa y su relación con los otros sujetos de la enunciación, se demuestra que la sacralidad o el sacrilegio del consumo de enteógenos depende de una serie de condiciones contextuales de 1926. Asi, durante la vanguardia algunos escritores se alejan de la embriaguez modernista por no encajar en sus particulares programas politicos como es el caso de Mariátegui y Vallejo sobre el opio; en contraste a quienes ejercen la defensa del indio y la tierra como Gamaliel Churata y Mario Chabes sobre la hoja de coca. De esta manera, los fumadores en literatura requieren estudios especificos para 
comprender su relación con lo que fuman como producto de la tierra y sus ideas alrededor del consumo. Al respecto, mediante el tabaco, el fumador de pipa amplifica su yo para trascender las fronteras de la posesión, el tiempo y el espacio, hasta advertirse deshumanizado. Así, similar al campesino devenido en obrero, el exquisito hombre que fuma deviene en animal que piensa.

\section{Referencias bibliográficas}

Castañeda, L. H. (2011). Reconfiguraciones del sujeto lírico en la poesía hispanoamericana de vanguardia: Oliverio Girondo y Gerardo Diego. Hispanic Poetry Review, 1-25.

Cornejo Polar, J. (2018). La poesía de César Atahualpa Rodríguez. En J. Cornejo Polar, Estudios de Literatura Peruana (pp. 191223). Lima: Fondo Editorial de la Universidad de Lima.

De Rosa, D. (2000). Sobre el héroe decadente. Thélème: Revista complutense de estudios franceses, 57-68.

Gallegos Díaz, C. (2006). Aportes a la teoría del sujeto poético. Espéculo Revista de Estudios Literarios, 1-33.

Lauer, M. (2001). La polémica del vanguardismo: 1916-1928. Lima: UNMSM.

Mansilla Torres, S. (2011). Sobre el sujeto lírico mestizo: una aproximación a la subjetividad en la poesía de las memorias culturales. Revista chilena de literatura, 69-90.

Muñoz Cabrejo, F. (2001). Diversiones públicas en Lima 1890-1920: la experiencia de la modernidad. Lima: Red para el Desarrollo de las Ciencias Sociales en el Perú.

Pantigoso Pecero, M. (1961). César Atahualpa Rodiguez y La torre de las paradojas. Lima: UNMSM.

- (1970). La espiral introyectiva en la poesía de César Atahualpa Rodriguez. Lima: UNMSM.

Quiroz, A. (2013). Historia de la corrupción en el Perú. Lima: Instituto de Defensa Legal. 
Sánchez Franco, M. S. (2007). La representación del sujeto aristócrata y del sujeto juvenil drogado en Historietas malignas de Clemente Palma. Lima: UNMSM.

Saravia, D. (2020). Migración china y orientalismo modernista: análisis en la revista Variedades (1909-1919). Lima: Ediciones MyL S.A.C.

Segura Zariquiegui, A. (2012). La melancolía en la poesía modernista peruana. Madrid: Universidad Autónoma de Madrid.

—. (2016). César Atahuallpa Rodríguez: La interiorización poética postmodernista peruana. Cartaphilus, 189-203.

Slawinski, J. (1989). Sobre la categoría de sujeto lírico. Textos y contextos. Una ojeada en la teoría literaria mundial, 333-346. 